Tersedia online di: http://ejournal-balitbang.kkp.go.id/index.php/jkpi
e-mail:jkpi.puslitbangkan@ gmail.com
JURNAL KEBIJAKANPERIKANANINDONESIA
Volume 8 Nomor 1 Mei 2016
p-ISSN: 1979-6366
e-ISSN: 2502-6550
Nomor Akreditasi: $626 /$ AU2 / P2MI-LIPI / 03/2015

\title{
STRATEGI PENGEMBANGAN PERIKANAN TANGKAP BERBASIS BUDIDAYA DI WADUK: STUDI KASUS INTRODUKSI IKAN BANDENG (Chanos chanos) DI WADUK SEMPOR, KABUPATEN KEBUMEN, JAWA TENGAH
}

\section{THE DEVELOPMENT STRATEGY OF CULTURE-BASED FISHERIES AT RESERVOIR ENVIRONMENT: THE CASE STUDY OF MILK FISH (ChanOS chanos) INTRODUCTION AT SEMPOR RESERVOIR, KEBUMEN REGENCY, CENTRAL JAVA}

\author{
Chairulwan Umar, Aisyah dan Endi Setiadi Kartamihardja \\ Pusat Penelitian dan Pengembangan Perikanan, Gd. Balitbang KP. 2 Jl. Pasir Putih II Ancol Timur, \\ Jakarta 14430-Indonesia \\ Teregistrasi I tanggal: 05 April 2016; Diterima setelah perbaikan tanggal: 09 Mei 2016; \\ Disetujui terbit tanggal: 11 Mei 2016
}

\begin{abstract}
ABSTRAK
Perikanan tangkap berbasis budidaya adalah upaya yang dilakukan untuk mengoptimalkan pemanfaatan produktivitas alami perairan melalui konversi sumber daya makanan alami menjadi biomassa ikan tanpa merusak lingkungan. Upaya tersebut adalah upaya yang sangat ekonomis dan ramah lingkungan. Dalam kasus ini, makanan alami yang tersedia di perairan waduk dimanfaatkan oleh ikan bandeng (Chanos chanos) menjadi biomassa ikan sehingga meningkatkan hasil tangkapan nelayan di perairan waduk Sempor, Kabupaten Kebumen, Jawa Tengah. Untuk mengoptimalkan produktivitas perairan waduk Sempor dalam memproduksi ikan secara berkelanjutan diperlukan strategi pengembangan yang meliputi: penebaran benih ikan bandeng secara berkala sesuai target ikan yang dipanen; penggalangan dana penebaran dari retribusi hasil tangkapan bandeng; penggunaan alat tangkap gill net dan jala dengan ukuran mata jaring sesuai ukuran ikan bandeng target; pembinaan kelompok nelayan (kelompok pengawas, kelompok pengolah dan pemasaran); dan pengembangan pengelolaan perikanan secara partisipatif dan terpadu. Perikanan tangkap berbasis budidaya ikan bandeng adalah salah satu opsi peningkatan produksi ikan yang direkomendasikan untuk diterapkan di perairan waduk lain yang memiliki karakteristik limnologi yang sama dengan waduk Sempor.
\end{abstract}

Kata Kunci : Perikanan tangkap berbasis budidaya; regulasi penangkapan; ko-manajemen; ikan bandeng; Waduk

\begin{abstract}
Culture-based fisheries is an effort to optimize the productivity of natural waters resources through the convertion of natural food resources to fish biomass without interfering reservoir environment. This practices are considered as economically and eco-friendly. In this case, available natural food resources was consumed by milk fish (Chanos chanos) and converted into fish flesh biomass so that the fishes catch in the Sempor Reservoir at Kebumen Regency, Central Java is increasing. To optimize the reservoir productivity and to increase and sustain fish production in the reservoir, some strategies were needed: restocking of milk fish regulary according to the harvested size of fish target; levy collection from milk fish catch for purchasing next season fish seed; mesh size regulation of gillnet and cash-net; improving the capacity of fisher group; and the development of participative and integrated fisheries management. It is recommended to implement this culture-based fisheries of milk fish in other reservoirs with the same limnological characteristics.
\end{abstract}

Keywords: Culture-based fisheries; fishing regulation; co-management; milk fish; reservoir 


\section{PENDAHULUAN}

Waduk Sempor berada di Kabupaten Kebumen, Jawa Tengah,merupakan salah satu dari tiga waduk (Waduk Wadaslintang dan Jembangan) yang secara geografis terletak pada $07^{\circ} 29^{\prime} \mathrm{LS}$ dan $109^{\circ} 29^{\prime}$ BT dengan fungsi utama untuk pengairan, bahan baku air minum, pembangkit listrik tenaga air (PLTA), pengendali banjir dan fungsi tambahan untuk perikanan dan pariwisata. Waduk Sempor mempunyai luas maksimum 560 ha dan volume air maksimum 46,5 juta $\mathrm{m}^{3}$ pada ketinggian muka air $73 \mathrm{~m}$ di atas permukaan laut (dpl) dengan luas minimum 56 ha dan volume air 5,5 juta $\mathrm{m}^{3}$ pada ketinggian muka air $43 \mathrm{~m}$ dpl sehingga berdasarkan luas dan volume tampung waduk, waduk ini tergolong waduk kecil. Pada kondisi kemarau panjang, dimana tinggi muka air waduk sangat rendah, pada tahun 2004 luas waduk ini menjadi sekitar 47,3 ha, sedangkan pada tahun 2014 luasnya hanya sekitar 19,27 ha dengan kedalaman air antara 5-6 $\mathrm{m}$ atau menurun sekitar 40,74\% (USGS, 2012). Fluktuasi luas dan volume air waduk yang tinggi tersebut antara lain disebabkan oleh sedimentasi dan perubahan cuaca ekstrim, terutama perubahan curah hujan dan aliran air yang masuk waduk (Setiawan, 2007).

Secara ekologi, Waduk Sempor mempunyai dua zona, yaitu zona perairan dalam yang meliputi bagian tengah dan outlet waduk, serta zona dangkal atau zona litoral (Umar et al., 2014). Zona litoral yang merupakan area potensial terjadinya proses fotosintesis dan metabolisme organisme akuatik mencapai $82 \%$ dari total luas waduk.

Kondisi perikanan terkini di Waduk Sempor menggambarkan berkurangnya beberapa jenis ikan asli, sebaliknya meningkatnya populasi jenis ikan asing invasifseperti ikan lohan (Cichlasoma trimaculatum). Ikan asing invasif ini dilaporkan pernah mendominasi hasil tangkapan nelayan setempat dan menurunkan ikan asli karena kompetisi ruang dan makanan. Kehadiran ikan asing invasif dan menurunnya ikan asli berpengaruh terhadap pendapatan nelayan karena ikan invasif yang tertangkap bernilai ekonomis rendah.

Teknologi perikanan tangkap berbasis budidaya (culture-based fisheries) merupakan teknologi pilihan yang dapat diterapkan dalam rangka meningkatkan produksi ikan di perairan waduk. Kegiatan penebaran dan perikanan tangkap berbasis budidaya merupakan beberapa bentuk teknologi pemulihan sumberdaya ikan (fisheries enhancement)(Kartamihardja et al., 2010). Sistem perikanan tangkap berbasis budidaya, berlandaskan pada penebaran benih ikan dari hasil budidaya (pembenihan) yang dilakukan secara rutin, ikan yang ditebar tumbuh dengan memanfaatkan makanan alami dan ikan tersebut tidak diharapkan untuk berkembang biak. Oleh karena itu, produktivitas perairan dan penebaran ikan secara reguler menjadi pertimbangan ilmiah dalam mengembangkan perikanan tangkap berbasis budidaya di suatu badan air. Teknologi perikanan tangkap berbasis budidaya termasuk teknologi yang sesuai diterapkan di perairan waduk yang tidak luas, efisien dalam memanfaatkan produktivitas alaminya, pengelolaannya mudah dan tidak berdampak negatif terhadap fungsi utama waduk (De Silva, 2015).

Penelitian ini bertujuan untuk memberikan gambaran bentuk upaya mengoptimalkan produktivitas waduk melalui pengembangan perikanan tangkap berbasis budidaya. Di Indonesia, teknologi perikanan tangkap berbasis budidaya telah dikembangkan di beberapa perairan waduk sejak tahun 1999 dan menunjukkan hasil yang baik (Kartamihardja, 2015), seperti di Waduk Darma (Kuningan-Jawa Barat), Waduk Ir. H. Djuanda (Jatiluhur-Jawa Barat), Waduk Malahayu (Brebes-Jawa Tengah), Waduk Gajah Mungkur (Wonogiri-Jawa Tengah) dan yang terakhir di Waduk Sempor (Kebumen-Jawa Tengah).

\section{KARAKTERISTIK LIMNO-BIOLOGI WADUK SEMPOR}

Berdasarkan karakteristik limnologisnya, Waduk Sempor termasuk perairan golongan kelas dua yang sesuai untuk rekreasi air, budidaya ikan, peternakan dan irigasi (Peraturan Pemerintah nomor 82 tahun 2001 tentang Pengelolaan Kualitas Air dan Pengendalian Pencemaran Air).

Hasil pengamatan beberapa parameter limnologi seperti berikut: konsentrasi nitrat $\left(\mathrm{NO}_{3}\right)$ yaitu $0,324-$ $0,511 \mathrm{mg} / \mathrm{L}$, fosfat $\left(\mathrm{PO}_{4}\right)$ yaitu $0,148-0,485 \mathrm{mg} / \mathrm{L}$ dan kecerahan air serta kelimpahan fitoplankton Waduk Sempor berkisar 25.961-252.968 sel/L, sedangkan menurut Suryandari\&Purnomo (2011), rata-rata kelimpahan fitoplanktonnya $218.570 \mathrm{sel} / \mathrm{L}$. Pola kelimpahan fitoplankton sejalan dengan fluktuasi tinggi muka air, dimana pada saat kelimpahan terendah terjadi pada bulan Agustus, tinggi muka air rata-rata pada bulan yang sama juga rendah.Konsentrasi nitrat dan fosfat serta kelimpahan fitoplankton yang cenderung meningkat bersamaan dengan peningkatan nutrien atau unsur hara yang terbawa masukan dari air sungai yang terjadi pada musim hujan.

Berdasarkan kriteria trofiknya, waduk Sempor termasuk ke dalam tipe eutrofik atau tingkat kesuburan yang tinggi (OECD, 1982). Tingkat trofik 
waduk Sempor mengalami peningkatan dari mesotrofik pada tahun 2009 (Kartamihardja, 2009) menjadi eutrofik pada tahun 2013 (Purnomo et al., 2013).

Kondisi bio-limnologi ini sesuai bagi jenis ikan planktivora (pemakan plankton), misalnya ikan bandeng karena bandeng tergolong pemakan plankton dan detritus. Juvenil ikan bandeng memakan Cyanobacteria, diatoms, detritus, alga hijau, udang kecil dan cacing, sedangkan bandeng dewasa mengkonsumsi plankton, tanaman bentik, larva ikan dan alga (Bagarinao, 1991). Di Waduk Ir. H. Djuanda makanan utama ikan bandeng adalah fitoplankton (50,16-77,76\%) dan zooplankton $(20,02-48,72 \%)$ (Tjahjo\& Purnamaningtyas, 2009;Aqil, 2010). Hasil penelitian tahun 2015 di Waduk Sempor menunjukan bahwa makanan utama ikan bandeng terdiri dari empat jenis makanan utama, yaitu fitoplankton, zooplankton, detritus dan makrofita.

\section{KERAGAAN PERIKANAN WADUK SEMPOR}

Sebagai salah satu dari tiga waduk yang terdapat di Kabupaten Kebumen selain dua waduk lainnya yaitu Wadaslintang dan Jembangan, Waduk Sempor berkontribusi sekitar 35\% dari total produksi perikanan di perairan umum (statistik Kab. Kebumen, 2014). Di waduk ini ditemukan tidak kurang dari 12 spesies ikan yang berasal dari 6 famili namun populasi beberapa jenis ikan mulai berkurang bahkan jarang tertangkap, misalnya ikan tawes (Barbonimus gonyonotus), mas (Cyprinus carpio) dan lunjar (Rasbora argyrotaenia)(Purnomo et al., 2013). Sebelum ikan bandeng ditebar, komposisi hasil tangkapan di Waduk Sempor terdiri dari ikan nila (Oreochromis niloticus), ceba atau kakul (Puntius binotatus), Iohan (Cichlasoma trimaculatum), betutu (Oxyeleotris marmorata), lele (Clarias batrachus), nilem (Osteochilushasselti), lobster air tawar (Cherax spp) serta gabus (Channa striata).

Pada tahun 2013, rata-rata produksi hasil tangkapan ikan di waduk ini sangat rendah hanya $2,3 \mathrm{~kg} /$ nelayan/hari dan menurun terus dari tahun ke tahun padahal potensi produksi ikan untuk pengembangan perikanan tangkap waduk Sempor berkisar antara 237-307 ton/th (Purnomo et al., 2013). Potensi produksi ikan tersebut berfluktuasi sesuai dengan fluktuasi tinggi muka air, luas permukaan air dan volume waduk. Potensi produksi ikan yang cukup tinggi tersebut belum dimanfaatkan secara optimal bagi peningkatan produksi ikan untuk kesejaheraan masyarakat nelayan setempat. Di sisi lain, secara morfometri waduk Sempormempunyai potensi zona limnetik yang produktif karena merupakan wilayah dimana sinar matahari masih tembus ke lapisan dalam sehingga kelimpahan fitoplankton sebagai makanan alami ikan relatif tinggi dibandingkan dengan waduk kecil lainnya.

Alat tangkap ikan yang digunakan nelayan di Waduk Sempor terdiri atas jaring insang (gill net), jala (cast net) dan pancing (line). Jaring insang dan jala merupakan alat tangkap utama sedangkan pancing umumnya digunakan oleh nelayan pendatang dan nelayan sambilan. Alat tangkap jaring insang yang digunakan mempunyai ukuran mata jaring antara 24 inci dengan panjang satu lembar (pis) $30 \mathrm{~m}$. Setiap nelayan umumnya memasang jaring insang antara 3-10 pis sedangkan jala berukuran mata jaring antara 2,5-3,5 inci. Sebelum ikan bandeng ditebarkan, hasil tangkapan jaring insang yang terdiri dari betutu, ceba, gabus, lobster, lohan, nila dan nilem lebih bervariasi dibandingkan dengan hasil tangkapan jala yang terdiri atas lohan, nila dan udang.

\section{PENEBARAN DAN PERKEMBANGAN PERIKANAN BANDENG}

Di Waduk Djuanda, penebaran ikan bandeng dengan kepadatan 250 ekor/ha telah mampu memanfaatkan kelimpahan fitoplankton di daerah pelagis dan meningkatkan total hasil tangkapan ikan (Kartamihardja, 2007; Kartamihardja, 2009). Di waduk Sempor, penebaran benih bandeng dengan ukuran panjang total antara 3-5 cm dilakukan pada Juni 2014 sebanyak 200.000 ekor dan September 2014 sebanyak 100.000 ekor(P4KSI, 2014). Pada September 2014, bandeng yang diperkirakan ditebar pada Juni telah mencapai ukuran panjang total antara 14,9-21,5 cm dengan berat antara 28-81 gram. Hasil tangkapan bandeng dari awal penebaran hingga November 2015 baik dari segi ukuran maupun jumlah yang tertangkap (ekor) mengalami peningkatan, namun hasil tangkapannya mulai menurun pada Desember 2015 (Gambar 1).Penurunan hasil tangkapan ini menunjukkan bahwa ikan bandeng di waduk hanya tumbuh tidak berkembang biak sehingga untuk mengganti ikan bandeng yang tertangkap perlu dilakukan penebaran kembali. 


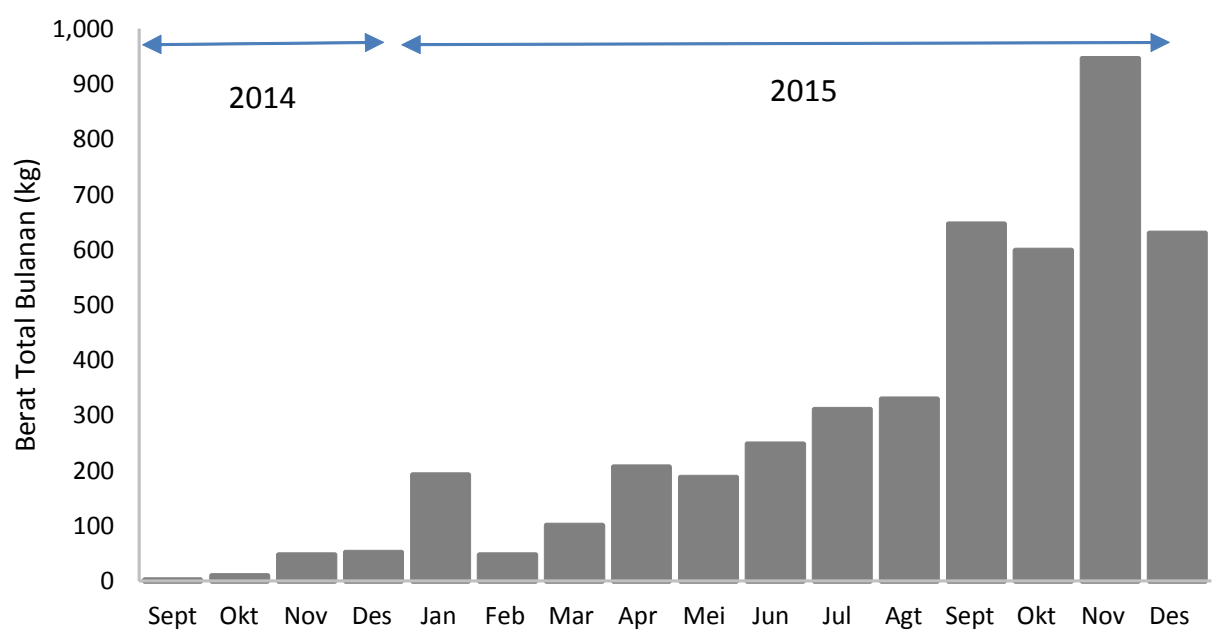

Gambar 1. Perkembangan hasil tangkapan ikan bandeng (Chanos chanos).

Figure 1. Catch fluctuation of milk fish (Chanos chanos).

Alat tangkap yang digunakan untuk menangkap bandeng adalah jaring insang, jala dan pancing. Berdasarkan komposisi hasil tangkapan jala dan jaring (dalam berat), terlihat bahwa peluang tertangkapnya bandeng oleh jala lebih tinggi dibandingkan dengan jaring insang (Gambar 2.). Hasil tangkapan jala yang relatif lebih tinggi dari jaring insang kemungkinan disebabkan oleh cara pengoperasian jala yang bersifat aktif, dijatuhkan/ditebarkan (falling gear) untuk mengurung ikan pada sasaran yang terlihat maupun tidak terlihat (Widodo \& Sasmita, 2013). Sementara jaring insang bersifat pasif, dengan cara pengoperasian menghadang arah renang gerombolan ikan baik pelagis maupun demersal yang menjadi sasaran tangkap sehingga terjerat/ terpuntal (entangled) padajaring.
Jaring insang yang berukuran mata jaring 2,5-3,5 inci merupakan yang paling banyak menangkap bandeng sedangkan jala pada ukuran mata jaring 2,53 inci. Bandeng yang tertangkap baik oleh alat tangkap jala maupun jaring pada umumnya berukuran panjang total antara $33-55 \mathrm{~cm}$ atau berat antara 3891264 gram. Berdasarkan hasil diskusi dengan masyarakat nelayan, ikan bandeng ukuran berat ratarata 300 gram merupakan ukuran yang ideal untuk proses pengolahan sebagai bandeng presto. Oleh karena itu, ukuran mata jaring yang direkomendasikan untuk jaring insang adalah 2,5 inci dan untuk mata jaring jala sebaiknya minimal 3 inci karena beroperasi di pinggir waduk.
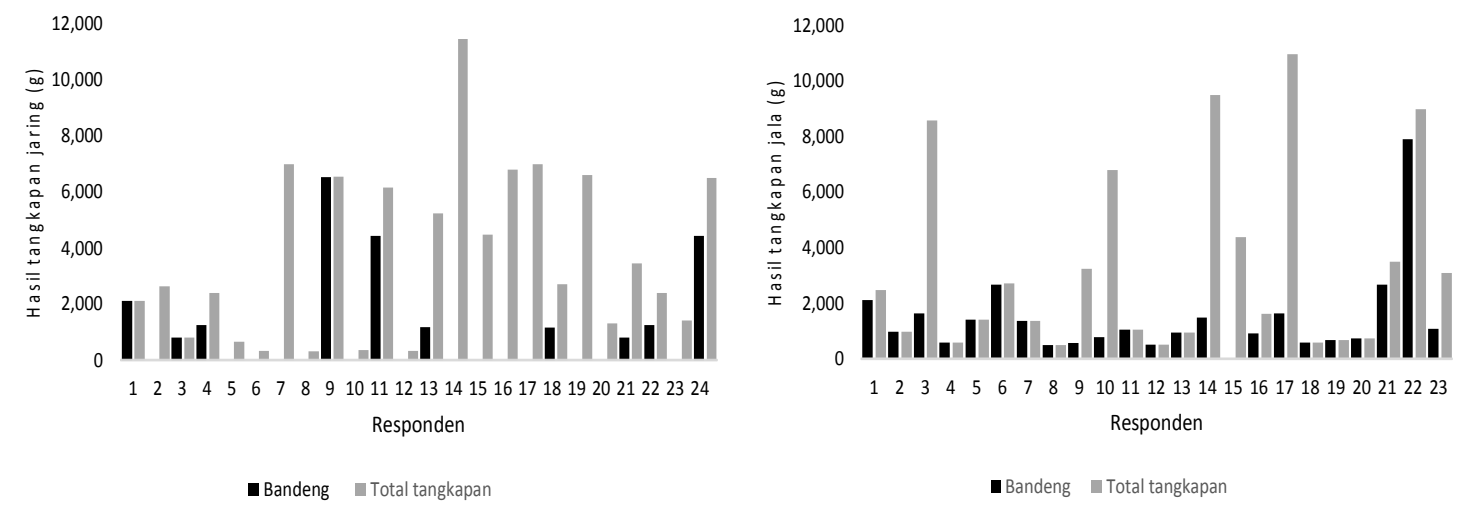

Gambar 2. Komposisi hasil tangkapan jaring insang dan jala di Waduk Sempor. Figure 2. Catch composition of gill net and cast net in Sempor Reservoir. 


\section{STRATEGI PENGELOLAAN PERIKANAN}

Untuk mengoptimalkan produktivitas perairan Waduk Sempor dalam memproduksi ikan secara berkelanjutan diperlukan beberapa strategi pengelolaan, yang meliputi: penebaran ikan bandeng secara berkala sesuai ukuran target panen, penggalangan dana penebaran dari retribusi hasil tangkapan bandeng, regulasi penggunaan alat tangkap jaring insang dan jala dengan ukuran mata jaring sesuai ukuran target, pembinaan kelompok nelayan (pengawas, pengolah dan pemasaran), dan pengembangan pengelolaan perikanan secara partisipatif (co-management) secara terpadu.

Sumber benih ikan pada penerapan sistem perikanan tangkap berbasis budidaya berasal dari basil pembenihan yang ditebarkan di waduk. Teknologi ini pada dasarnya diaplikasikan di suatu badan air yang berukuran relatif kecil baik yang sifatnya permanen maupun tidak, dengan tujuan dalam rangka menyediakan tambahan penghasilan bagi masyarakat yang ada di sekitar badan air tersebut (Lorenzen et al., 2001).Oleh karena ikan bandeng yang ditebarkan tidak bisa berkembangbiak di waduk maka populasi ikan bandeng akan menurun menurut waktu seiring dengan meningkatnya jumlah ikan yang tertangkap. Untuk mengganti jumlah ikan bandeng yang tertangkap perlu dilakukan penebaran benih ikan kembali.

Penebaran benih bandeng tersebut perlu disesuaikan dengan potensi produksi ikan, target ukuran ikan yang diharapkan dan kondisi tinggi muka air waduk. Berdasarkan potensi produksi ikannya, jumlah optimum benih bandeng yang harus ditebarkan adalah 240.000 ekor per tahun (Purnomo et al., 2013) sedangkan berdasarkan target ukuran ikan bandeng yang diharapkan oleh nelayan adalah 300 gram per ekor dimana ukuran tersebut dapat dicapai sekitar 56 bulan setelah penebaran maka frekwensi penebaran ikan bandeng harus dilakukan dua kali dalam setahun masing-masing sebanyak 120.000 ekor. Waktu penebaran sebaiknya dilakukan pada waktu muka air waduk tinggi menjelang surut yaitu sekitar Januari dan pada waktu tinggi muka air waduk mulai naik, yaitu sekitar Agustus (Gambar 3.). Pada waktu air waduk terendah atau volume air waduk minimum, ikan bandeng sudah mencapai ukuran ekonomis yang siap dipanen. Pada waktu air waduk mulai menggenangi bagian litoral yang tadinya kekeringan, pasokan makanan alami terutama fitoplankton akan tinggi yang merupakan makanan bagi benih ikan bandeng yang ditebar. Dipilihnya penebaran ikan bandeng pada bulan Januari dan Agustus karena pada bulan tersebut fluktuasi muka air tinggi mulai turun dan fluktuasi muka air mulai naik. Selain itu pada waktu tersebut pasokan makanan alami terutama fitoplankton sebagai makanan benih ikan cukup tinggi.

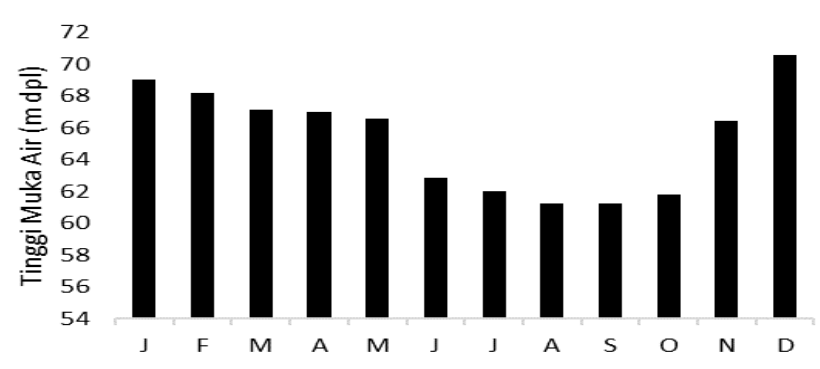

Gambar 3. Fluktuasi tinggi muka air waduk Sempor tahun 2014

(Sumber data : Balai Besar Wilayah Sungai Serayu-Opak)

Figure 3. Water level fluctuation of Sempor Reservoir in 2014

(Source data : Serayu-Opak River Basin Territory)

Penebaran ikan bandeng secara mandiri yang dilakukan oleh masyarakat nelayan perlu dikembangkan dan untuk keperluan tersebut masyarakat dapat mengumpulkan dana retribusi dari hasil tangkapan ikan bandeng. Adanya dana retribusi dan besarannya merupakan hasil kesepakatan bersama nelayan. Di waduk Jatiluhur, nelayan mengumpulkan dana penebaran sebesar 600 rupiah dari setiap satu kilogram ikan bandeng yang tertangkap (Kartamihardja \& Umar, 2004). Pengumpulan dana untuk keperluan pembelian benih ikan tersebut pernah dilakukan pula di Waduk Malahayu dan Waduk Wonogiri di Jawa Tengah. Di Waduk Sempor, kelompok nelayan telah sepakat untuk memberlakukan penarikan retribusi sebesar 1000 rupiah dari setiap kilogram ikan bandeng yang tertangkap. Dana retribusi tersebut dikelola oleh kelompok nelayan dan selanjutnya digunakan untuk membeli benih bandeng sehingga penebaran secara swadaya bisa dilakukan secara berkala.

Penggunaan alat tangkap tertentu yang direkomendasikan berguna dalam mengoptimalkan produktivitas nelayan di Waduk Sempor agar tercapai tujuan utama kegiatan penebaran yaitu mensejahterakan masyarakat. Berdasarkan atas hasil tangkapan bandeng dengan alat jala relatif lebih tinggi dibandingkan jaring insang maka jala direkomendasikan sebagai alat tangkap yang menjadi bantuan bagi nelayan di Waduk Sempor dari Pemerintah Daerah Kabupaten Kebumen. 
Pembinaan kelompok nelayan merupakan bagian dari strategi pengembangan perikanan tangkap berbasis budidaya di Waduk Sempor. Kelembagaan nelayan yang sudah mulai terbentuk pada September 2014 setelah adanya kegiatan penebaran yaitu Kelompok Masyarakat Pengawas (Pokmaswas) Mina Sari Indah yang membawahi 3 kelompok nelayan, yaitu KUB Mina Tirta Mina (24 orang), KUB Mina Telaga Sari (10 orang), KUB Mina Sari Asih (15 orang) perlu terus dibina dan dikembangkan. Pokmaswas berfungsi sebagai pengontrol pemanfaatan sumber daya ikan dan lingkungannya agar tercapai pemanfaatan sumber daya secara optimal dan berkelanjutan. Kelembagaan masyarakat yang terbentuk tidak hanya berperan dalam pengelolaan sumber daya ikan tetapi juga harus ikut serta dalam memeliharaekosistem waduk beserta lingkungan di sekitarnya. Kondisi Waduk Sempor mengalami sedimentasi yang relatif tinggi yang antara laindisebabkan oleh buruknya tata guna lahan di sekitar waduk serta tipologi struktur bangunan waduk. Dalam kurun waktu 30 tahun terakhir telah terjadi peningkatan luas lahan kritis dan penggundulan hutan (Ariyanto \& Widijanto, 2008; Julia, 2012). Padahal telah ada PERDA nomor 23 tahun 2012 mengenai rencana tata ruang wilayah Kabupaten Kebumen tahun 2011-2031. Di dalamnya tercantum mengenai kawasan sempadan danau atau waduk berupa kawasan sabuk hijau sepanjang perairan dengan jarak $50-100$ meter dari titik pasang tertinggi seluas kurang lebih 245 ha (dua ratus empat puluh lima hektar) yang berada di Waduk Wadaslintang Kecamatan Padureso dan Waduk Sempor Kecamatan Sempor.

Di samping itu telah dilakukan beberapa penelitian mengenai skenario tata guna lahan dan bangunan pengendali sedimen untuk mengatasi laju sedimentasi yang masuk ke Waduk Sempor. Hasil penelitian menunjukan bahwa kombinasi skenario tataguna lahan dengan persentase hutan seluas $73,3 \%$ di sungai ordo 3 adalah kombinasi terbaik sehingga mampu menekan laju sedimentasi hingga $1,3 \mathrm{~mm} /$ tahun $(71,1 \%$ dari potensi sedimen yang mengalir) (Julia, 2012).

Sumber daya perikanan perairan umum daratan di Kabupaten Kebumen terutama di Waduk Sempor telah memberi manfaat bagi masyarakat di sekitarnya. Pengelolaan perikanan secara partisipatif (comanagement) merupakan pilihan terbaik yang perlu dikembangkan di Waduk Sempor. Pengelolaan perikanan tersebut merupakan pembagian kewenangan antara pemerintah dan masyarakat dalam mengelola sumber daya perikanan. Dalam hal ini peran serta masyarakat diakui dan pemerintah bertindak sebagai pengarah dan pembina dalam mencapai tujuan pengelolaan perikanan yang telah ditetapkan secara bersama. Ko-manajemen juga dapat berfungsi untuk mengurangi konflik antar nelayan melalui proses demokrasi partisipatif. Oleh karena, otorita pengelola Waduk Sempor adalah Balai Pengelola Wilayah Sungai Serayu-Opak dan waduk berfungsi serbaguna sedangkan kegiatan perikanan merupakan fungsi tambahan, maka pengelolaan ekosistem waduk harus dilakukan secara terpadu (Kartamihardja, 1993). Kegiatan penebaran ikan dalam pengembangan perikanan tangkap berbasis budidaya di waduk perlu dikoordinasikan dengan pihak pengelola waduk untuk mengontrol volume air waduk dalam kaitannya dengan kebutuhan perikanan.

\section{KESIMPULAN DAN REKOMENDASI Kesimpulan}

Perikanan tangkap berbasis budidaya adalah upaya yang dilakukan untuk mengoptimalkan pemanfaatan produktivitas alami perairan melalui konversi sumberdaya makanan alami menjadi biomassa ikan tanpa merusak lingkungan. Dalam kasus ini, produktivitas makanan alami yang tersedia di perairan waduk dimanfaatkan oleh ikan bandeng (Chanos chanos) menjadi biomasa ikan sehingga meningkatkan hasil tangkapan nelayan di perairan waduk Sempor. Perikanan tangkap berbasis budidaya ikan bandeng adalah salah satu opsi peningkatan produksi ikan di waduk yang direkomendasikan untuk diterapkan di perairan waduk lain yang memiliki karakteristik limnologi yang sama dengan waduk Sempor.

\section{Rekomendasi}

Beberapa strategi pengembangan diperlukan untuk mengoptimalkan produktivitas perairan waduk Sempor dalam memproduksi ikan secara berkelanjutan, meliputi: penebaran benih ikan bandeng secara berkala sesuai target ikan yang dipanen yang dilakukan pada waktu muka air waduk tinggi menjelang surut dan menjelang naik; penggalangan dana penebaran dari retribusi hasil tangkapan bandeng untuk keperluan pembelian kembali benih ikan; penggunaan alat tangkap jaring insang dan jala dengan ukuran mata jaring sesuai ukuran ikan bandeng target; pembinaan kelompok nelayan (kelompok pengawas, kelompok pengolah dan pemasaran); pengembangan pengelolaan perikanan secara partisipatif dan terpadu.

\section{PERSANTUNAN}

Terima kasih disampaikan kepada Pusat Penelitian dan Pengembangan Perikanan yang telah mendanai keberlangsungan jurnal ini melalui kegiatan 
Pematangan Teknologi CBF Ikan Bandeng dan Pengendalian Ikan Asing Invasif di Waduk Sempor, Kebumen, Jawa Tengah Tahun Anggaran 2015.

\section{DAFTAR PUSTAKA}

Aqil, D.I. (2010). Pemanfaatan plankton sebagai sumber makanan ikan bandeng (Chanos chanos) di perairan Waduk Ir. H. Juanda, Jawa Barat. Skripsi. Program Studi Biologi (p. 57). Fakultas Sains dan Teknologi. Universitas Syarif Hidayatullah. Jakarta.

Ariyanto, D P. \& Widijanto, H. (2008). Kajian klasifikasi bahaya erosi dengan sistem informasi geografi di daerah hulu Waduk sempor, Gombong. Sains Tanah-Jurnal IImiah IImu Tanah dan Agroklimatologi 5 (II), 121-128.

Bagarinao, T. U. (1991). Biology of milkfish (Chanos chanos Forsskal) (p.105). Iloilo Philippines: Aquaculture Department, Southeast Asian Fisheries Development Center.

De-Silva, S. (2015). Culture-based fisheries: why, what, where, how and for whom? In S. S. DeSilva (ed). Perspectives on culture based fisheries developments in Asia (pp. 17-25). NACA Monograph Series No. 3.

Julia, H. (2008). Studi analisa ekonomi pada pengelolaan air Waduk Sempor. Universitas Gajah Mada.

Kartamihardja, E. S. (1993). Perencanaan Pengelolaan Perikanan Terpadu di Waduk Kedungumbo, Jawa Tengah. Prosiding Simposium Perikanan Indonesia I, 25-27 Agustus 1993. Jakarta.

Kartamihardja, E.S. (2007). Spektra ukuran biomasa plankton dan potensi pemanfaatannya bagi komunitas ikan di zona limnetik Waduk Ir. Djuanda, Jawa Barat (p.165). Disertasi, Sekolah Pasca Sarjana IPB.

Kartamihardja, E.S. (2009). Pendugaan Potensi Produksi Ikan di Perairan Danau dan Waduk Indonesia untuk Pengembangan Perikanan Tangkap (p.20). Laporan Teknis. Pusat Penelitian Perikanan dan Konservasi Sumber Daya Ikan. Badan Litbang Kelautan dan Perikanan.

Kartamihardja, E. S. (2009). Mengapa ikan bandeng di introduksi di Waduk Djuanda, Jawa Barat? Dalam Kartamihardja, E. S., Sunarno, M. T. D.,
Wiadnyana, N.N., Rahardjo, M. F \& Krismono (Eds). Forum Nasional Pemacuan Sumberdaya Ikan II (p. 1-14). Departemen Kelautan dan Perikanan.

Kartamihardja, E. S. (2010). Petunjuk teknis pemulihan sumber daya ikan di perairan umum daratan Indonesia (p.72). Pusat Penelitian Pengelolaan Perikanan dan Konservasi Sumber Daya Ikan.

Kartamihardja, E.S. (2013). Stock Enhancement In Indonesian Lakes and Reservoirs Fisheries. Ind. Fish. Res. J. 18(2), 91-100.

Kartamihardja, E. S. (2015). Potential of culture-based fisheries in Indonesian inland waters. In S. S. DeSilva (ed.), Perspectives on culture-based fisheries developments in Asia (pp. 73-81). Bangkok, Thailand: Network of Aquaculture Centres in Asia-Pacific.

Lorenzen, K., Amarasinghe, U.S., Bartley, D.M., Bell, J.D., Bilio, M., de Silva, S.S., Garaway, C.J., Hartmann, W.D., Kapetsky, J.M., Laleye, P., Moreau, J., Sugunan, V.V. \& Swar, D.B. (2001). Strategic Review of enhancements and culturebased fisheries. In R.P. Subasinghe, P. Bueno, M.J. Phillips, C. Hough, S.E. McGladdery \& J.R. Arthur, eds. Aquaculture in the Third Millennium. Technical Proceedings of the Conference on Aquaculture in the Third Millennium, Bangkok, Thailand, 20-25 February 2000.

NACA, Bangkok and FAO, Rome, 221-237.

OEDC. (1982). Eutrophication of waters - monitoring, assessment and control (p.154). Organization for Economic and Cooperative Development.

Purnomo, K., Warsa, A\& Kartamihardja, E.S. (2013). Daya dukung dan Potensi Produksi Ikan Waduk Sempor di Kabupaten Kebumen, Provinsi Jawa Tengah. J.Lit.Perikan.Ind. 19 (4), 203-212.

Setiawan, A. (2007). Kajian Keandalan Waduk Sempor. J. Tehnik Sipil. 7(3), 279-286.

Suryandari, A. \& Purnomo, K. (2011). Studi kebiasaan makananan jenis-jenis ikan di beberapa situ dan waduk di Jawa Barat sebagai informasi dasar dalam upaya pengkayaan stok ikan (p. 11). Prosiding Forum Nasional Pemacuan Sumber Daya Ikan III, 18 Oktober 2011. Badan Riset Kelautan dan Perikanan. 
Tjahjo, D. W \& Purnamaningtyas, S. E. (2009). Evaluasi kemampuan ikan bandeng dan nila tebaran dalam memanfaatkan kelimpahan fitoplankton di Waduk Ir. H. Djuanda (p. 11). Prosiding Forum Nasional Pemacuan Sumber Daya Ikan II.

Umar, C., Kartamihardja, E. S., Prianto, E., Priatno, Y., Fahmi, Z., Gunawan, A \& Budi, E. K. (2014). Model penerapan iptek CBF ikan bandeng dan pengendalian ikan asing invasif di Waduk sempor-
Kabupaten Kebumen dan Waduk SermoKabupaten Kulon Progo (p.59). Laporan Teknis. Pusat Penelitian Pengelolaan Perikanan dan Konservasi Sumberdaya Ikan.

USGS. (2012). U.S. Geological Survey. Retrieved from http://usgs.gov/.

Widodo, S.S. (2013). Katalog alat penangkapan ikan Indonesia (p.358). Semarang-Jawa Tengah: Balai Bepan Ikan. 